\title{
Evolution of Nuclear Medicine Physics in the UK
}

\author{
Richard S. Lawson
}

Most nuclear medicine staff will know that the phenomenon of radioactivity was discovered by a Frenchman, Henri Becquerel [1]. However very few are aware that an Englishman nearly beat him to it. Silvanus Thompson was professor of physics at Finsbury Technical College in London and in 1896 he, like Becquerel, had been investigating the properties of certain phosphorescent minerals [2]. On 26th February he wrote to George Stokes, who was the President of The Royal Society, saying that he had discovered that uranium nitrate produced rays that penetrated paper and blackened a photographic plate. Stokes replied on 29th February advising him to publish without delay, but by 2 nd March it was too late because on that day Becquerel presented his similar findings to the Academy of Sciences in Paris [2]. Nevertheless Sylvanus Thompson did make a contribution to medical imaging because in 1897 he became the first President of the Roentgen Society which later became the British Institute of Radiology [2].

Ernest Rutherford was born in New Zealand, but in 1895 he came to England to study in Cambridge under another Thompson, J.J. Thompson who discovered the electron. Here Rutherford identified two different components of the Becquerel radiation which he called alpha and beta rays [1]. In 1898 Rutherford took a post at McGill University in Montreal where, with Frederick Soddy, he investigated radioactive series and developed the disintegration theory of radioactivity [1]. However in 1907 he returned to the UK to take a position as Professor of Physics at Manchester University. Here, with Hans Geiger and Ernest Marsden, he performed the famous experiments on alpha particle scattering which led to him

R.S. Lawson

Department of Nuclear Medicine, Central Manchester Nuclear Medicine Centre,

Manchester, UK 
proposing the nuclear theory of the atom. For this he was awarded the Nobel Prize in Chemistry in 1908 and in 1919 he became Professor of Physics in Cambridge [1]. For this work he is often known as the 'Father of Nuclear Physics'. Frederick Soddy returned to England to work at University College London where he and William Ramsay identified the alpha particle as a helium nucleus. In 1904 Soddy became a lecturer in physical chemistry at Glasgow University where he formulated the concept of isotopes of elements and for this he was awarded the Nobel Prize in Chemistry in 1921 [1].

One of Rutherford's students in Manchester in 1911 was a Hungarian chemist, George de Hevesy. Rutherford set him the task of trying to chemically separate the radioactive radium $\mathrm{D}$ from non-radioactive lead in pitchblende. His failure to do this led him to the conclusion that radium D must be an isotope of lead which would make an ideal tracer for stable lead [3]. De Hevesy is credited with the first ever use of a radioactive tracer when he added some radium $\mathrm{D}$ to the left-overs of a meal in his digs. When he was able to detect the radioactivity in the food that his landlady served up later in the week he was able to demonstrate that she was recycling old food rather than serving up fresh as she claimed [3]. De Hevesy subsequently went on to use his radioactive isotopes for more serious purposes as tracers in chemical reactions, in plants and then in animals [1]. For this work he received the Nobel Prize in Chemistry in 1943 and it is no wonder that he is known as the 'Father of Nuclear Medicine' [3].

In 1903 William Crookes, working in London, developed the first scintillation detector using zinc sulphide and this was used as the basis of scintillation detectors until it was superseded by sodium iodide some 40 years later [4]. However many early studies used a Geiger counter which was invented by Hans Geiger in Manchester in 1908 and later improved by Geiger and Walther Müller [4]. It is still used today as a versatile radiation detector.

The earliest nuclear medicine studies were performed without any imaging, just using blood or urine samples or external counting, initially with Geiger counters and later with scintillation detectors. One of the standard reference works for these studies was written by Norman Veall and Herbert Vetter in 1958 [5]. Norman Veall was a medical physicist at Hammersmith Hospital and then at Guy's Hospital who later became head of the Radioisotope Section at the MRC Clinical Research Centre at Northwick Park Hospital. He was talented at developing new equipment and pioneering its use for a wide variety of nuclear medicine studies. He developed the technique of measuring glomerular filtration rate using ${ }^{51} \mathrm{Cr}$ EDTA and pioneered techniques for thyroid function, blood flow, cardiac output and many others [6].

The first nuclear medicine study that produced anything like an 'image' of organ function was performed in Liverpool. In 1948 George Ansell and Joseph Rotblat used some of the first ${ }^{131} \mathrm{I}$ produced from the new reactor at Harwell to map the distribution of iodine uptake in a patient's thyroid [7]. For this they used a collimated Geiger counter that was manually positioned at different positions over the patient's neck. Like many other physicists Rotblat had worked on the Manhattan project during the war, but he quickly left the project on moral grounds and returned to his 
research in nuclear physics at Liverpool University. He became interested in the medical uses of radiation because he was determined that his work should be used for peace not war. In 1949 he became Professor of Physics at St Bartholomew's Hospital in London. In 1957, along with Bertrand Russell, Albert Einstein and others, he founded the Pugwash Conferences on Science and World Affairs, an organisation of scientists working for peace, and in 1995 he was awarded the Nobel Peace prize [1].

Automation of this mapping process led to development of the rectilinear scanner and the first British scanner was constructed in 1951 at the Royal Cancer Hospital in Sutton (now the Royal Marsden Hospital) by Val Mayneord. It could scan a Geiger counter repeatedly backwards and forwards over a small area building up a display on a cathode ray tube display [4]. In 1957 John Mallard at the Hammersmith Hospital produced a larger scanner with two scintillation detectors and a novel colour display [8]. This may have been the first whole-body clinical rectilinear scanner in Europe [9]. It was used for ${ }^{131}$ I thyroid imaging and also for coincidence detection of positron emitting radionuclides in the brain $[8,9]$. The existence of positrons and the phenomenon of positron-electron annihilation had been predicted by Paul Dirac whist working in Cambridge and he received the Nobel Prize for Physics in 1933 [1].

The first gamma camera in Europe was made by Ekco Electronics of Southendon-Sea (formerly E.K. Cole Ltd). It improved on Anger's original design by having a storage oscilloscope display so that the image could be viewed in real time. The prototype was tested by John Mallard and Melvyn Myers at the Hammersmith Hospital in 1963 [9]. In 1965 John Mallard became Professor of Medical Physics at the University of Aberdeen and in 1967 they installed their first commercial gamma camera made by Nuclear Enterprises of Edinburgh [9]. In 1973 Mallard's Department developed the Aberdeen Section Scanner which was able to produce single tomographic slices of the brain from a pair of scintillation counters which scanned and then rotated around the patient's head [9]. In 1978 the Aberdeen department also developed a gamma camera SPECT system by mounting a Nuclear Enterprises gamma camera on a rotating gantry [9]. Nuclear Enterprises had started making gamma cameras after they purchased the nuclear instrumentation section of Ekco Electronics and subsequently Scintronix, another Edinburgh Company, continued development of a Scottish gamma camera. Figure 5.1 shows a Nuclear Enterprises gamma camera in use in Manchester Royal Infirmary about 1970.

Since the era of global equipment manufacturers, the opportunities for major developments in equipment by hospital physicists has largely disappeared. However, UK physicists have continued to play a vital role in developments and quality improvements in nuclear medicine procedures. Their contributions have often been as scientific and technical support to particular clinical problems, so it is more appropriate to mention them in the relevant clinical applications chapters of this book.

In 1994 the British Nuclear Medicine Society inaugurated a medal in memory of the pioneering work done by Norman Veall. The Norman Veall Medal is awarded 


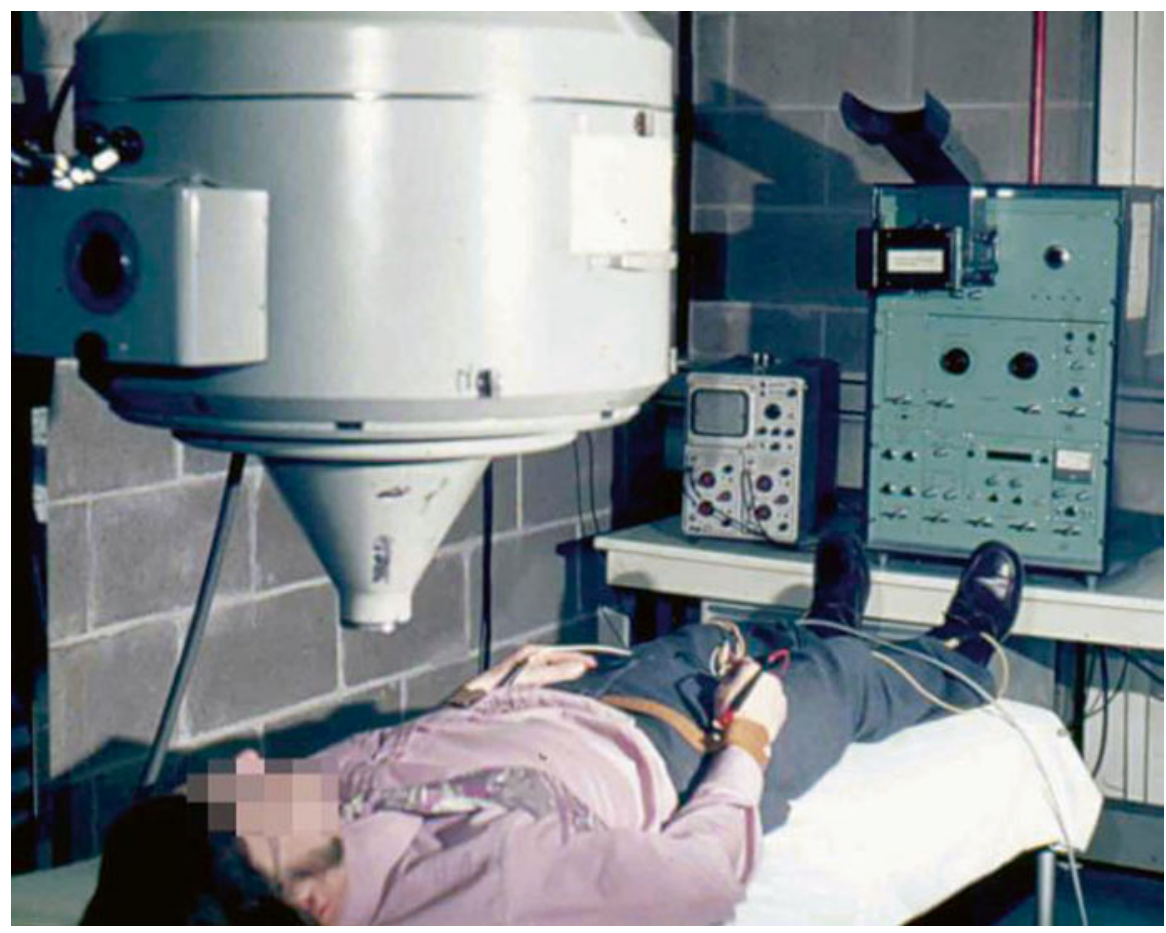

Fig. 5.1 A Nuclear Enterprises gamma camera circa 1970 (Copyright Institute of Physics and Engineering in Medicine 2013. Reproduced with permission)

annually to a clinical scientist who has made an outstanding contribution to the science and/or practice of nuclear medicine in the United Kingdom [10]. The list of recipients of the Norman Veall medal is therefore a good indication of some of the physicists and other scientists who have made important contributions to nuclear medicine in the UK in recent years. Recipients include Terry Jones and John Clark from the Hammersmith Hospital, John Mallard and Peter Sharpe from Aberdeen, Roger Ekins and Andrew Todd-Pokropek from University College Hospital, David Barber from Sheffield, John Fleming from Southampton, Alex Houston from Portsmouth, Peter Jarritt from Belfast, Malcolm Frier and Alan Perkins from Nottingham, Alex Elliott from Glasgow, David Williams from Sunderland, Robert Shields and Richard Lawson from Manchester, Steve Mather from Queen Mary University London, Glen Blake from Guy's and St Thomas' Hospital, Bill Thomson from Birmingham and Paul Maltby from Liverpool. These people have been involved in many different areas of nuclear medicine and their spread across the country shows that scientists continue to make important contributions to nuclear medicine throughout the UK. 
Open Access This chapter is distributed under the terms of the Creative Commons AttributionNoncommercial 2.5 License (http://creativecommons.org/licenses/by-nc/2.5/) which permits any noncommercial use, distribution, and reproduction in any medium, provided the original author(s) and source are credited.

The images or other third party material in this chapter are included in the work's Creative Commons license, unless indicated otherwise in the credit line; if such material is not included in the work's Creative Commons license and the respective action is not permitted by statutory regulation, users will need to obtain permission from the license holder to duplicate, adapt or reproduce the material.

\section{References}

1. L'Annunziata MF. Radioactivity: introduction and history. Amsterdam: Elsevier; 2007.

2. Thompson JS, Thompson HG. Silvanus Phillips Thompson, his life and letters. London: Fisher Unwin; 1920.

3. Myers WG. Georg Charles de Hevesy: the father of nuclear medicine. J Nucl Med. 1979;20(6):590-4.

4. McCready VR. Milestones in nuclear medicine. Eur J Nucl Med. 2000;27(Suppl):S49-79.

5. Veall N, Vetter H. Radioisotope techniques in clinical research and diagnosis. London: Butterworth \& Co; 1958.

6. Maisey MN. Obituary, Dr Norman Veall. Nucl Med Commun. 1992;13:294.

7. Ansell G, Rotblat J. Radioactive iodine as a diagnostic aid for intrathoracic goitre. Br J Radiol. 1948;21:552-9.

8. Mallard J, Trott NG. Some aspects of the history of nuclear medicine in the United Kingdom. Semin Nucl Med. 1979;9:203-17.

9. Mallard JR. Hevesy memorial medal lecture 1985. Nucl Med Commun. 1987;8:691-710.

10. British Nuclear Medicine Society. The Norman Veal medal. http://www.bnms.org.uk/about/ awards-prizes/the-norman-veall-medal.html. Last viewed 26 Oct 2015. 


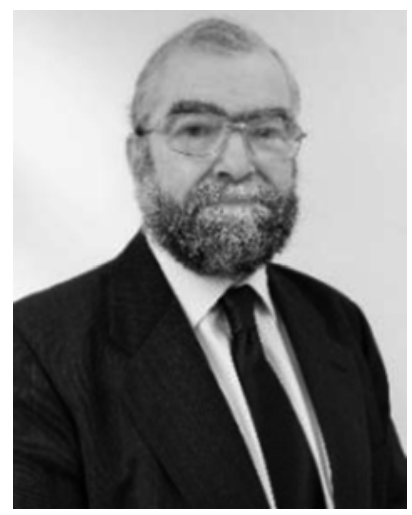

Richard S. Lawson Richard Lawson is now retired, but for 36 years he worked as a medical physicist in the Nuclear Medicine Department of Manchester Royal Infirmary which later became the Central Manchester Nuclear Medicine Centre. During that time he has taken a particular interest in renal studies and in teaching nuclear medicine. He was honoured to receive the Silver Medal of the Society and College of Radiographers for services to the teaching of radiographers and the Norman Veall Medal of the British Nuclear Medicine Society.

Nuclear medicine in Manchester Royal Infirmary started in 1967 when Tito Testa came over from Argentina bringing his skills as a nuclear medicine physician to conduct research for the Department of Surgical Gastroenterology. Initially radioisotope work was part of the Department of Medical Physics headed by Brian Pullan and in 1969 they moved into newly built facilities in a so-called 'Multi-purpose Building'. Robert Shields joined the hospital as medical physicist in 1971 and Nuclear Medicine became established as a Department in its own right, with Tito being appointed as its first consultant in 1974. Working together for over 30 years Tito and Robert have led a team of doctors, physicists, radiopharmacists and technologists who built up an international reputation for developing new nuclear medicine techniques, collaborating with clinical colleagues to introduce them into clinical practice. They have also always been involved with teaching and training nuclear medicine staff. In 1970 Tito's team developed pancreatic scanning techniques using ${ }^{75} \mathrm{Se}$ selenomethionine, first with a rectilinear scanner and later with a gamma camera and a computer subtraction technique to remove liver activity. In 1978 Paddy O'Reilly developed the technique of diuresis renography which is now used routinely throughout the world. The Department also pioneered the use of ${ }^{123} \mathrm{I}$ hippuran for gamma camera renography and promoted the use of nuclear medicine in monitoring kidney transplants. The team wrote a textbook on nuclear medicine in urology and nephrology and developed computer software for accurate analysis of renograms. The Department was an early investigator in the use of ${ }^{99 \mathrm{~m}} \mathrm{Tc}$ HMPAO for brain perfusion imaging in dementia and an advocate of ventilation lung scans, with research on the use of ${ }^{81 \mathrm{~m}} \mathrm{Kr}$ and ${ }^{99 \mathrm{~m}} \mathrm{Tc}$ technegas led by Jackie James. More recently the Department has built up a reputation as a centre of excellence for nuclear cardiology led by Parthiban Arumugam and has introduced dose reduction techniques in several areas. Mary Prescott took over the reins of the Department from Tito when she became Clinical Director in 1999 and, together with Robert, introduced the PET service. In 2009 the Department finally moved out of the 40 year old Multi-purpose Building into brand new accommodation in the Central Manchester Nuclear Medicine Centre which incorporated a dedicated paediatric unit. In 2010 they became the only UK centre outside London to introduce a routine ${ }^{82} \mathrm{Rb}$ PET myocardial perfusion service, reducing both scan times and radiation dose for patients. Currently Parthiban Arumugam is the Clinical Director, Christine Tonge leads the physics team and Beverley Ellis heads the radiopharmacy. 